\title{
COMPARISON OF SINGLE AND COMPOUND WASHING OF REMEDIATING PB CONTAMINATED SOIL OF NON-FERROUS SMELTERS
}

\author{
GuO, W. $.^{1,2}-$ ZHANG, H. Z. ${ }^{1 *}-$ YIN, X. X.1,3 - WANG, Z. L. ${ }^{1,4}$ \\ ${ }^{I}$ School of Water Resources and Environment, China University of Geosciences \\ \#29 Xueyuan Road, Haidian District, Beijing 100083, P. R. China \\ ${ }^{2}$ Taiyuan Environmental Monitoring Center, Taiyuan Ecology and Environment Bureau \\ Taiyuan 030002, P. R. China \\ ${ }^{3}$ Research Center for Eco-Environmental Sciences, Chinese Academy of Sciences \\ Beijing 100085, P. R. China \\ ${ }^{4}$ Beijing Zhongdihongke Environmental Science and Technology Co. Ltd. \\ Beijing 100011, P. R. China \\ *Corresponding author \\ e-mail: huanzhen@cugb.edu.cn; phone: +86-10-8232-1068 \\ (Received $13^{\text {th }}$ Jul 2019; accepted $25^{\text {th }}$ Nov 2019)
}

\begin{abstract}
Orthogonal and single factor experiments were used to investigate the remediation effect of single and compound washing on $\mathrm{Pb}$ contaminated soil from a typical non-ferrous metal smelter. The optimal washing conditions and speciation distribution of $\mathrm{Pb}$ were determined. The obtained removal efficiency of $\mathrm{Pb}$ from the soil is $68.35 \%$, which could be remedied to less than "risk intervention values $\left(\mathrm{Pb}<2500 \mathrm{mg} \cdot \mathrm{kg}^{-1}\right)$ for soil contamination of the development land" in soil environmental quality standard China (GB36600-2018) when the compound ratio of $\mathrm{HCl} \&$ Rhamnolipid is 1:1, the ratio of liquid-solid is 10:1 and the washing time is $1080 \mathrm{~min}$. The removal efficiency of $\mathrm{Pb}$ are significantly higher when using compound eluents compared to single eluents, such as $\mathrm{HCl}$, EDTA, oxalic acid and rhamnolipid. Moreover, compound eluents can effectively remove active $\mathrm{Pb}$ from soil, which greatly reduces their bioavailability and environmental risk.
\end{abstract}

Keywords: heavy metal pollution, soil washing, rhamnolipid, speciation distribution, kinetic analysis

\section{Introduction}

Global industrialization is accelerating at a continuous rate. The development of the nonferrous metal mining, smelting and processing industry in particular has led to the severe degradation of soils due to heavy metal pollution, and such contamination incidents have also attracted much attention (Park et al., 2002; Li et al., 2013; de Andrade Lima and Bernardez, 2017). Many experimental remediation technologies for heavy metal contaminated soils, such as soil exchange, solidification and stabilization, vitrification, and phytoremediation microbial remediation, have been developed (Dermont et al., 2008; Voglar and Leštan, 2011; Reza et al., 2015). However, they are difficult to implement in practical remediation projects of heavy metal contaminated soil due to their limitations, characteristics, secondary pollution, cost end effect on contaminated soil (Moutsatsou et al., 2006; Chen et al., 2017).

Soil contaminated by heavy metals in non-ferrous metal smelters is characterized by its high pollution intensity, complex forms, and is often accompanied by other heavy metals, which brings great challenges to its remediation (Bacon and Dinev, 2005; Burges et al., 2017). However, chemical washing has a promising application prospect as it is highly efficient, low cost, and has a short cycle (Abumaizar and Smith, 1999; de Andrade Lima and Bernardez, 
2017). The type of eluent is the key to the repair effect, and the mechanism and removal capacity of different types of eluents vary. Common eluents include: inorganic eluents, artificial chelating agents, natural organic acid, biological surfactant and compound eluents (Dermont et al., 2008). For example, inorganic eluents can quickly and effectively remove heavy metals from the soil, and is low cost, but may damage the soil structure and biology. Artificial chelating agents can effectively remove heavy metals by self-chelating, but they are not easily biodegradable, and therefore cause secondary soil pollution. The costs of biological surfactants are often too high, which limits their engineering applications (Chen et al., 2017). Compound washing can not only improve the removal efficiency of pollutants, but also avoids secondary pollution and high cost associated with a single eluent through the synergistic solubilization of compound reagents.

In this paper, $\mathrm{Pb}$ contaminated soil from typical non-ferrous metal smelter was selected as the research object, and remedial target is to satisfy with the requirement of the "Risk control standard for soil contamination of development land" in soil environmental quality standard China (GB36600-2018). Hydrochloric Acid (HCl), Oxalic Acid, Ethylene Diamine Tetraacetic Acid (EDTA) and Rhamnolipid were selected as eluents, and oscillating washing experiments were carried out on the contaminated soil by single and compound washing. The optimal combination of eluents and conditions of washing were determined, and the washing kineties and washing mechanism were explored to establish the theoretical basis and technical support for the actual remediation project of heavy metal contaminated soil in non-ferrous metal smelters.

\section{Materials and methods}

\section{Soil samples collection and preservation}

Soil samples were collected from the surface layer $(0-100 \mathrm{~cm})$ of a typical non-ferrous metal smelter in Yunnan, China $(103.329,26.455)$. Remove the impurities, such as stones and plant roots, and air-dry naturally in the absence of light. After crushing, they are fully mixed and evenly stored in plastic bags. Subsequently, soil samples are screened according to the specific requirements of the experiment. Some of the soil samples were screened with 100 meshes for the determination of soil physical and chemical properties and heavy metals. Another part of the soil samples was screened with 20 meshes for washing experiments. The basic characteristics and test methods of the soil sample are shown in Table 1 and Fig. 1.

Table 1. Basic characteristics of contaminated soil

\begin{tabular}{c|c|c}
\hline Parameter & Detection method & Value \\
\hline Soil type & $/$ & Red soil \\
Soil size $(\%)$ & LY/T 1225-1999 & $/$ \\
Clay $(<0.002 \mathrm{~mm})$ & $/$ & 3.57 \\
Silt $(0.002 \sim 0.05 \mathrm{~mm})$ & $/$ & 57.41 \\
Sand $(0.05 \sim 2 \mathrm{~mm})$ & $/$ & 38.02 \\
$\mathrm{pH}$ & $\mathrm{NY} / \mathrm{T} \mathrm{1377-2007}$ & 6.70 \\
Organic matter content $\left(\mathrm{g} \cdot \mathrm{kg}^{-1}\right)$ & LY/T 1237-1999 & 61.2 \\
$\mathrm{CEC}\left(\mathrm{cmol} \cdot \mathrm{kg}^{-1}\right)$ & LY/T 1243-1999 & 13.5 \\
$\mathrm{TN}\left(\mathrm{g} \cdot \mathrm{kg}^{-1}\right)$ & LY/T 1228-2015 & 0.95 \\
$\mathrm{TP}\left(\mathrm{g} \cdot \mathrm{kg}^{-1}\right)$ & LY/T 1232-2015 & 2.69 \\
Total $\mathrm{Pb}\left(\mathrm{mg}^{\mathrm{k}} \cdot \mathrm{kg}^{-1}\right)$ & GB/T 17141-1997 & 7500.00 \\
\hline
\end{tabular}

\footnotetext{
${ }^{\mathrm{a}}$ China standard detection method for soil, ${ }^{\mathrm{b}}$ Cation exchange capacity
} 

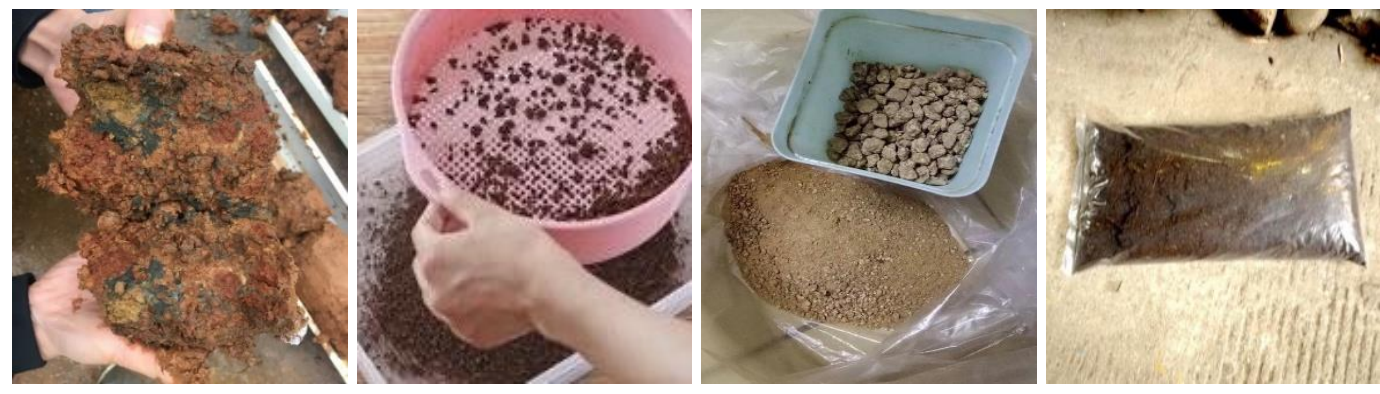

Figure 1. Soil samples collection and preservation

\section{Experimental equipment}

Inductively Coupled Plasma Optical Emission Spectrometer (ICP-OES-5100, Agilent Technologies), Thermostatic oscillator (THZ-82, Guohua electric appliance Co., Ltd., China), Ultraviolet spectrophotometer (Cary 4000, Agilent Technologies), electronic balance (CP-214, Ohaus instrument), High speed tabletop refrigerated centrifuge (LXJII B, Shanghai anting scientific instrument, China), Microwave digestion instrument (Mars-6, CEM Corporation) were used in the experiment. All experimental water is deionized water.

\section{Method of washing experiment}

The washing experiment conditions of single eluents are shown in Table 2 according to the principle of an orthogonal experiment (Cui et al., 2007; Zhao et al., 2013; Zuo et al., 2016).

Table 2. Orthogonal experiment conditions for single eluents

\begin{tabular}{c|c|c|c|c|c|c}
\hline Levels & $\begin{array}{c}\text { HCl } \\
\text { (M) }\end{array}$ & $\begin{array}{c}\text { Oxalic acid } \\
(\mathbf{M})\end{array}$ & $\begin{array}{c}\text { EDTA } \\
(\mathbf{M})\end{array}$ & $\begin{array}{c}\text { Rhamnolipid } \\
(\boldsymbol{\%})\end{array}$ & $\begin{array}{c}\text { Liquid-solid } \\
\text { ratio }\end{array}$ & $\begin{array}{c}\text { Washing } \\
\text { time (min) }\end{array}$ \\
\hline 1 & 0.1 & 0.1 & 0.01 & 0.25 & $5: 1$ & 60 \\
2 & 0.5 & 0.2 & 0.05 & 0.5 & $8: 1$ & 180 \\
3 & 1.0 & 0.5 & 0.1 & 1.0 & $10: 1$ & 480 \\
4 & 2.0 & 1.0 & 0.2 & 2.0 & $15: 1$ & 900 \\
\hline
\end{tabular}

A single factor experiment was used for compound washing, and the basic specific experimental methods were carried out in the following order: (1) Determination of the optimum compound ratio: $\mathrm{HCl}$ was compounded with EDTA and Rhamnolipid (2\%), respectively. The compound ratios were set as 3:1, 2:1, 1:1, 1:2, and 1:3. The liquid-solid ratio was 8:1, and the washing time was $480 \mathrm{~min}$; (2) Determination of optimal liquidsolid ratio: The compound ratio of $\mathrm{HCl} \&$ EDTA was 1:1, the compound ratio of $\mathrm{HCl} \&$ Rhamnolipid was 1:2, and the washing time was $480 \mathrm{~min}$. The liquid-solid ratio gradients were set to $3: 15: 1,8: 1,10: 1,15: 1$, and 20:1; (3) Determination of the optimum washing time: The compound ratio of $\mathrm{HCl} \&$ EDTA was selected for 1: 1, and liquid-solid ratio for 10: 1 . The compound ratio of $\mathrm{HCl} \&$ Rhamnolipid as 1: 2, and liquid-solid ratio for 15: 1 . The washing times for the two compound eluents were set at $60,180,300,480$, $720,1080,1440$, and $2160 \mathrm{~min}$. 
Soil samples of $3.00 \mathrm{~g}$ were weighed and packed into $100 \mathrm{~mL}$ centrifugal tubes. The eluents were added according to the experimental methods to oscillate for a given time at $210 \mathrm{RPM}$ at room temperature, centrifuged at $5000 \mathrm{RPM}$ for $6 \mathrm{~min}$, and the supernatant was filtered with a $0.45 \mu \mathrm{m}$ filter membrane. The contents of $\mathrm{Pb}$ were determined by ICP-OES.

All data were averaged by three groups of parallel experiments.

\section{Determination method}

In order to determine the distribution of heavy metal speciation in the soil before and after washing, the continuous extraction method of modified BCR was selected for the determination of $\mathrm{Pb}$ speciation in the soil (Tessier et al., 1979; Ashraf et al., 2012): (1) Acid extractable: add $40 \mathrm{~mL}$ of $0.1 \mathrm{M} \mathrm{CH}_{3} \mathrm{COOH}$ to $1.00 \mathrm{~g}$ of soil samples, shaken at $210 \mathrm{RPM}$ for $16 \mathrm{~h}$ at $(22 \pm 5)^{\circ} \mathrm{C}$, and centrifuged at $3000 \mathrm{RPM}$ for $20 \mathrm{~min}$; (2) Reducible: $40 \mathrm{~mL}$ of $0.5 \mathrm{M} \mathrm{NH}_{2} \mathrm{OH} \cdot \mathrm{HCl}$ was added to the residue, and shaken at $(22 \pm 5)^{\circ} \mathrm{C}$ for $16 \mathrm{~h}$, centrifuged at 3000 RPM for $20 \mathrm{~min}$; (3) Oxidizable: $10 \mathrm{~mL}$ of $\mathrm{H}_{2} \mathrm{O}_{2}$ was added to the residue at room temperature for $1 \mathrm{~h}$, and $10 \mathrm{~mL}$ of $\mathrm{H}_{2} \mathrm{O}_{2}$ was added again at $(85 \pm 2)^{\circ} \mathrm{C}$ and maintained for $1 \mathrm{~h}$, evaporated to near dryness, then $50 \mathrm{~mL}$ of $1 \mathrm{M} \mathrm{CH}_{3} \mathrm{COONH}_{4}$ was added, shaken at $(22 \pm 5)^{\circ} \mathrm{C}$ for $16 \mathrm{~h}$, and centrifuged at $3000 \mathrm{RPM}$ for $20 \mathrm{~min}$; (4) Residual: residual residue of $0.10 \mathrm{~g}$ was weighted and $10 \mathrm{~mL} \mathrm{HNO}_{3}, 1 \mathrm{~mL} \mathrm{HClO}_{4}$ and $1 \mathrm{~mL} \mathrm{HF}$ were added. The residue was microwaved until clear and transparent.

The content of various forms of $\mathrm{Pb}$ was determined by ICP-OES.

\section{Methods of data processing and analysis}

In this study, the ratio of heavy metal content in washing solution to original heavy metal content in contaminated soil was used to calculate the removal rate of $\mathrm{Pb}$; and the results of washing were analyzed by Origin 2017.

\section{Method of washing kinetics}

In order to better understand the process of $\mathrm{Pb}$ washing in soil, three different models, Elovich equation, Two-constant equation, First-order equation, were selected to analyze and evaluate the washing kinetics data by least squares regression.

Elovich equation (Eq.1) contains a series of reactions including solute diffusion and surface activation in the liquid phase. Two-constant equation (Eq.2) is applicable to the dynamic system process with relatively complex reaction. First-order equation (Eq.3) reflects the relationship between reaction equilibrium concentration and reaction rate. Their expressions are as follows:

$$
\begin{gathered}
S=A+B \ln t \\
\ln S=A+B \ln t \\
\ln S=\ln S_{\text {max }}+B t
\end{gathered}
$$

where, $S\left(\mathrm{mg} \cdot \mathrm{kg}^{-1}\right)$ was the washing amount of $\mathrm{Pb}, S_{\max }\left(\mathrm{mg} \cdot \mathrm{kg}^{-1}\right)$ was the total washing amount at equilibrium, $A$ and $B$ were both constants, and $t(\mathrm{~min})$ was the washing time. The determination coefficient $\left(R^{2}\right)$ is used to judge the significance and merits of the model. The larger $R^{2}$ indicating that the higher the fitting degree, the better the model. 


\section{Results and discussion}

\section{Effect of single eluent washing conditions}

The experiment results are shown in Table 3 Table 6.

Table 3 shows that the concentration of $\mathrm{HCl}$ is the key factor affecting the removal rate of $\mathrm{Pb}$. The higher the concentration, the higher the removal efficiency of $\mathrm{Pb}$ in soil, with the highest removal rate of $39.22 \%$. However, there was no significant change in the removal rate of $\mathrm{Pb}$ in soil when $\mathrm{HCl}$ exceeds $1.0 \mathrm{~mol} \cdot \mathrm{L}^{-1}$, and increasing $\mathrm{HCl}$ concentration leads to the destruction of soil structure and physic-chemical properties, and increases the cost of remediating the contaminated soil (Moutsatsou et al., 2006). The washing process of $\mathrm{HCl}$ is mainly the result of the interaction of $\mathrm{H}^{+}$promoting the dissolution of solid heavy metals and $\mathrm{Cl}^{-}$complexation promoting the formation of metal ion complexes.

Table 3. Orthogonal experiment and results of $\mathrm{HCl}$ washing

\begin{tabular}{c|c|c|c|c}
\hline No. & HCl $(\mathbf{M})$ & Liquid-solid ratio & Washing time (min) & Pb Removal rate (\%) \\
\hline 1 & 0.1 & $5: 1$ & 60 & 5.22 \\
2 & 0.1 & $8: 1$ & 180 & 7.94 \\
3 & 0.1 & $10: 1$ & 480 & 10.40 \\
4 & 0.1 & $15: 1$ & 900 & 12.43 \\
5 & 0.5 & $5: 1$ & 480 & 16.94 \\
6 & 0.5 & $8: 1$ & 900 & 18.71 \\
7 & 0.5 & $10: 1$ & 60 & 23.35 \\
8 & 0.5 & $15: 1$ & 180 & 29.34 \\
9 & 1.0 & $5: 1$ & 900 & 12.03 \\
10 & 1.0 & $8: 1$ & 60 & 16.96 \\
11 & 1.0 & $10: 1$ & 180 & 27.53 \\
12 & 1.0 & $15: 1$ & 480 & 31.20 \\
13 & 2.0 & $5: 1$ & 180 & 19.43 \\
14 & 2.0 & $8: 1$ & 480 & 21.74 \\
15 & 2.0 & $10: 1$ & 900 & 24.73 \\
16 & 2.0 & $15: 1$ & 60 & 39.22 \\
\hline$R(P b)$ & 0.173 & 0.146 & 0.041 & - \\
\hline
\end{tabular}

Oxalic acid is a kind of natural organic acid eluent, which has the characteristics of extensive existence and easy biodegradation. It can be seen from Table 4 that the oxalic acid has little effect on removing $\mathrm{Pb}$ from soil, only about $1 \%$, regardless of the concentration of oxalic acid. The main reason is that oxalic acid is one of the dicarboxylic acids, and has few reaction sites, which provides limited acidity and concentration of oxalate ion, and provides fewer reaction sites. In addition, oxalate ion reacts with $\mathrm{Pb}$ released from soil to produce insoluble compound $\mathrm{C}_{2} \mathrm{O}_{4} \mathrm{~Pb}$, whose standard solubility product constant is $4.8 \times 10^{-10}$ (Wei et al., 2016), which further inhibits the migration of metal ions to the aqueous phase, resulting in a poor washing effect.

It can be seen from Table 5 that EDTA has a strong extraction efficiency for $\mathrm{Pb}$ in soil, and removal effect increases with the increase of EDTA concentration, up to $43.41 \%$. This is due to its strong complexing ability and easy formation of 1:1 soluble complex with metals. The equilibrium constant of Pb-EDTA complex is 19.0 (Zhang et al., 2010; Qiao et al., 2017), which can further promote the desorption of $\mathrm{Pb}$ from the surface of soil 
particles and inhibit the re-adsorption of desorbed heavy metals. However, EDTA can easily cause secondary pollution to soil due to its own difficulty in degradation, and the instability of its chelates with heavy metals may bring potential environmental risks (Wei et al., 2016). Therefore, the optimal elution concentration of EDTA is $0.2 \mathrm{~mol} \cdot \mathrm{L}^{-1}$.

Table 4. Orthogonal experiment and results of Oxalic acid washing

\begin{tabular}{c|c|c|c|c}
\hline No. & Oxalic Acid (M) & Liquid-solid ratio & Washing time (h) & Pb Removal rate (\%) \\
\hline 1 & 0.1 & $5: 1$ & 60 & 0.10 \\
2 & 0.1 & $8: 1$ & 180 & 0.10 \\
3 & 0.1 & $10: 1$ & 480 & 0.13 \\
4 & 0.1 & $15: 1$ & 900 & 0.19 \\
5 & 0.2 & $5: 1$ & 480 & 0.07 \\
6 & 0.2 & $8: 1$ & 900 & 0.11 \\
7 & 0.2 & $10: 1$ & 60 & 0.58 \\
8 & 0.2 & $15: 1$ & 180 & 0.41 \\
9 & 0.5 & $5: 1$ & 900 & 0.02 \\
10 & 0.5 & $8: 1$ & 60 & 0.46 \\
11 & 0.5 & $10: 1$ & 180 & 0.61 \\
12 & 0.5 & $15: 1$ & 480 & 0.92 \\
13 & 1.0 & $5: 1$ & 180 & 0.42 \\
14 & 1.0 & $8: 1$ & 480 & 0.65 \\
15 & 1.0 & $10: 1$ & 900 & 1.11 \\
16 & 1.0 & $15: 1$ & 60 & 1.34 \\
\hline$R(P b)$ & 0.007 & 0.006 & 0.002 & - \\
\hline
\end{tabular}

Table 5. Orthogonal experiment and results of EDTA washing

\begin{tabular}{c|c|c|c|c}
\hline No. & EDTA $(\mathbf{M})$ & Liquid-solid ratio & Washing time $(\mathbf{h})$ & Pb Removal rate $(\boldsymbol{\%})$ \\
\hline 1 & 0.05 & $5: 1$ & 60 & 8.81 \\
2 & 0.05 & $8: 1$ & 180 & 10.59 \\
3 & 0.05 & $10: 1$ & 480 & 13.36 \\
4 & 0.05 & $15: 1$ & 900 & 10.02 \\
5 & 0.1 & $5: 1$ & 480 & 24.29 \\
6 & 0.1 & $8: 1$ & 900 & 18.34 \\
7 & 0.1 & $10: 1$ & 60 & 29.50 \\
8 & 0.1 & $15: 1$ & 180 & 26.82 \\
9 & 0.2 & $5: 1$ & 900 & 36.84 \\
10 & 0.2 & $8: 1$ & 60 & 40.17 \\
11 & 0.2 & $10: 1$ & 180 & 31.50 \\
12 & 0.2 & $15: 1$ & 480 & 36.46 \\
13 & 0.5 & $5: 1$ & 180 & 29.88 \\
14 & 0.5 & $8: 1$ & 480 & 41.57 \\
15 & 0.5 & $10: 1$ & 900 & 43.41 \\
16 & 0.5 & $15: 1$ & 60 & 37.94 \\
\hline$R(P b)$ & 0.275 & 0.045 & 0.044 & - \\
\hline
\end{tabular}

Rhamnolipid, an environmentally friendly anionic biological surfactant, can complexes with heavy metal ions by its own special hydroxyl and carboxyl structure, and can also reduce the surface tension of eluent and weaken the adhesion of heavy metal ions 
to soil (Nitschke et al., 2010). However, as shown in Table 6, rhamnolipid washing alone is less effective in removing $\mathrm{Pb}$ from contaminated soil, with a maximum efficiency of less than $2.0 \%$. The reason is that rhamnolipid is a $\mathrm{pH}$ neutral substance and can only remove water-soluble heavy metal ions, which is consistent with the research results of Zhou et al. (Wen et al., 2009; Zhou et al., 2017). Therefore, it must be combined with other acid eluents in order to wash heavy metals in soil more efficiently and economically.

Table 6. Orthogonal experiment and results of Rhamnolipid washing

\begin{tabular}{c|c|c|c|c}
\hline No. & Rhamnolipid (\%) & Liquid-solid ratio & $\begin{array}{c}\text { Washing time } \\
\text { (h) }\end{array}$ & Pb Removal rate (\%) \\
\hline 1 & 0.5 & $5: 1$ & 60 & 0.01 \\
2 & 0.5 & $8: 1$ & 180 & 0.06 \\
3 & 0.5 & $10: 1$ & 480 & 0.14 \\
4 & 0.5 & $15: 1$ & 900 & 0.03 \\
5 & 1.0 & $5: 1$ & 480 & 0.01 \\
6 & 1.0 & $8: 1$ & 900 & 0.22 \\
7 & 1.0 & $10: 1$ & 60 & 0.33 \\
8 & 1.0 & $15: 1$ & 180 & 0.36 \\
9 & 2.0 & $5: 1$ & 900 & 0.15 \\
10 & 2.0 & $8: 1$ & 60 & 0.31 \\
11 & 2.0 & $10: 1$ & 180 & 0.67 \\
12 & 2.0 & $15: 1$ & 480 & 0.73 \\
13 & 5.0 & $5: 1$ & 180 & 0.38 \\
14 & 5.0 & $8: 1$ & 480 & 0.77 \\
15 & 5.0 & $10: 1$ & 900 & 1.08 \\
16 & 5.0 & $15: 1$ & 60 & 1.33 \\
\hline$R(P b)$ & 0.008 & 0.005 & 0.001 & - \\
\hline
\end{tabular}

In addition, by comparing the magnitude of the Range $(R)$ of orthogonal experiments, the influence degree of washing conditions for single eluents on the removal rate of $\mathrm{Pb}$ can be shown as follows: Eluent Concentration > Liquid-Solid Ratio > Washing Time.

In summary, there are great differences in the removal efficiency of heavy metals in soil by four kinds of single eluents. Among them, $\mathrm{HCl}$ and EDTA had better removal efficiency of $\mathrm{Pb}$ in soil, optimum washing conditions of $\mathrm{HCl}$ and EDTA were $1 \mathrm{~mol} \cdot \mathrm{L}^{-1}$, $0.2 \mathrm{~mol} \cdot \mathrm{L}^{-1}$, respectively; the liquid-solid ratios were $15: 1$ and $8: 1$; the washing time of both was $480 \mathrm{~min}$; Oxalic acid is not suitable for remediation of contaminated soil in this site because of its poor washing effect; rhamnolipid needs to be combined with acid eluents in order to fully play its role.

\section{Effect of compound eluent washing conditions}

Compound eluents are optimized by compounding different types of single eluents, which mainly utilize the synergistic effect of different agents to further improve the removal efficiency of pollutants, and can avoid the secondary pollution and high cost of the single eluent. $\mathrm{HCl}$ was compounded with EDTA and rhamnolipid according to the orthogonal experimental results of single eluent, and the elution conditions were optimized by single factor experiments of compound washing. 


\section{Effect of the compound ratio of eluent on washing efficiency}

It can be seen from Fig. 2 that with the increase of the compound ratio of $\mathrm{HCl} \&$ EDTA, the removal rate of $\mathrm{Pb}$ first increase and then decrease. The removal rates of $\mathrm{Pb}$ are the highest (up to $60.36 \%$ ) when the ratio of $\mathrm{HCl} \&$ EDTA is $1: 1$. However, for $\mathrm{HCl}$ $\&$ Rhamnolipid, the higher the compound ratio, the better the removal efficiency of heavy metals, but when the compound ratio exceeds 1:2, the removal rate does not change much. In addition, the removal rate of $\mathrm{Pb}$ by compound eluents were better than that by single eluents.

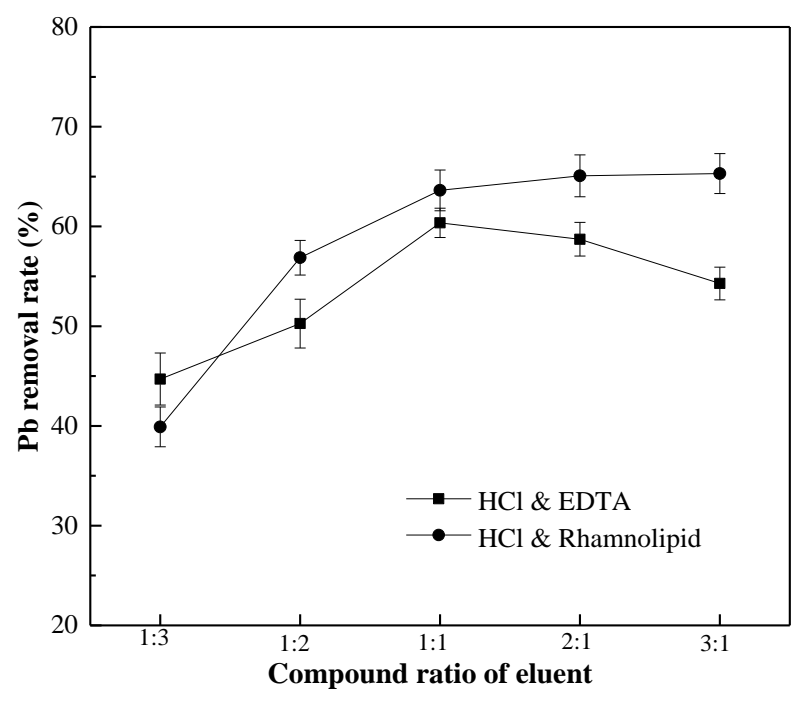

Figure 2. Effect of compound ratio on Pb removal rate

For $\mathrm{HCl} \&$ EDTA combined elution, the elution mechanism is mainly as follows: (1) The acid solubility of $\mathrm{H}^{+}$and the complexation of $\mathrm{Cl}^{-}$provided by $\mathrm{HCl}$; (2) EDTA can not only reduce the surface tension of the eluent, but also form a stable complex $\mathrm{Pb}$ EDTA with a coordination ratio of $1: 1$ with $\mathrm{Pb}$; (3) the synergistic solubilization among different agents. However, for $\mathrm{HCl} \&$ Rhamnolipid, besides (1) and (3), rhamnolipid is an anionic biosurfactant, which can not only reduce the surface tension of the eluent, but also form stable complexes with the special hydroxyl and carboxyl structures of the eluent and the $\mathrm{Pb}$ released from the soil.

\section{Effect of liquid-solid ratio and washing time on washing efficiency}

It can be concluded from Fig. 3(a) that with the increase of liquid-solid ratio, the removal rate of $\mathrm{Pb}$ in the soil of the two kinds of compound eluents are generally increasing; however, rate of removal increases slowly when it reaches a certain liquid-solid ratio. The essence of the increase of liquid-solid ratio is the increase of the amount of eluent, which leads to the increasing removal rate of heavy metals. The optimal liquid-solid ratio of both $\mathrm{HCl} \&$ EDTA and $\mathrm{HCl} \&$ Rhamnolipid was 10:1, according to the removal rate of $\mathrm{Pb}$ and the cost of remediation.

Washing time is a key factor that determines whether the eluent can interact adequately with the heavy metal pollutants in soil. Appropriate washing time can not only shorten the period of soil remediation, but also save costs. As can be seen from Fig. 3(b), the longer the washing time, the higher the removal efficiency of the two kinds of compound 
eluents. However, when washing time exceeds a certain limit, the removal efficiency of heavy metals does not exhibit much change. Therefore, the washing time of $\mathrm{HCl} \&$ EDTA was $720 \mathrm{~min}$, while that of $\mathrm{HCl} \&$ Rhamnolipid was $1080 \mathrm{~min}$.

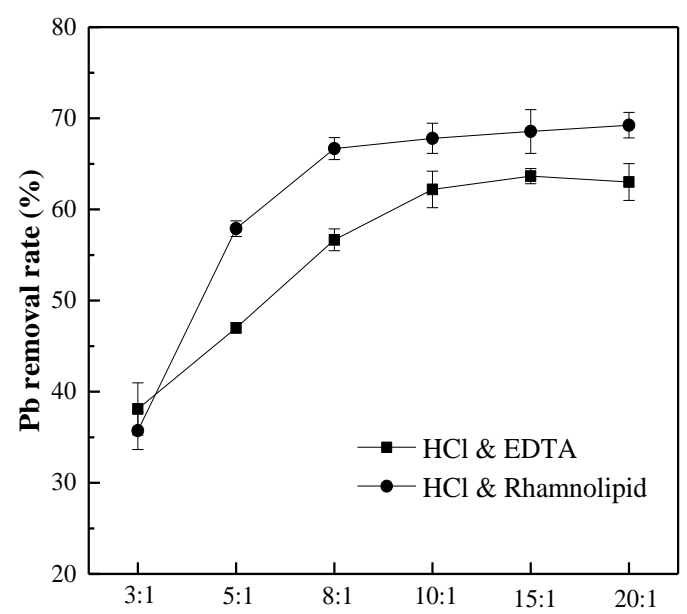

(a) Liquid-solid ratio

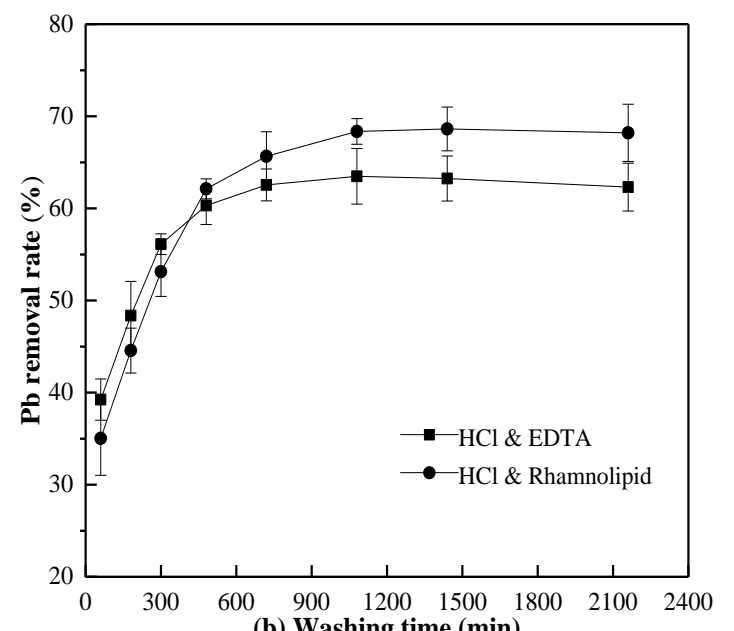

(b) Washing time (min)

Figure 3. Effect of liquid-solid ratio and washing time on washing efficiency

Therefore, considering various factors of soil remediation, such as washing cost, secondary pollution, etc., $\mathrm{HCl} \&$ Rhamnolipid compound washing effect is better, the optimum mixed ratio is $1: 1$, the liquid-solid ratio is $15: 1$, the washing time is $1080 \mathrm{~min}$, and the removal rate of $\mathrm{Pb}$ in soil is $68.35 \%$, which can be repaired to meet "risk intervention values $\left(\mathrm{Pb}\right.$ content $\left.<2500 \mathrm{mg} \cdot \mathrm{kg}^{-1}\right)$ for soil contamination of the development land" in soil environmental quality standard China (GB36600-2018).

\section{Kinetics of compound washing}

In order to better understand the process of $\mathrm{Pb}$ washing in soil, three different models, Elovich equation, Two-constant equation, First-order equation, were selected to analyze and evaluate the washing kinetics data by least squares regression, and the fitting results are shown in Table 7.

Table 7. Fitting results of three different models

\begin{tabular}{c|c|c|c}
\hline Equation & $\begin{array}{c}\text { Elovich equation } \\
\boldsymbol{S}=\mathbf{A}+\mathbf{B} \ln \boldsymbol{t}\end{array}$ & $\begin{array}{c}\text { Two-constant equation } \\
\boldsymbol{l n} \boldsymbol{S}=\mathbf{A}+\mathbf{B} \boldsymbol{l n} \boldsymbol{t}\end{array}$ & $\begin{array}{c}\text { First-order equation } \\
\boldsymbol{l n} \boldsymbol{S}=\boldsymbol{l n S m a x}+\mathbf{B} \boldsymbol{t}\end{array}$ \\
\hline Fitting result & $\mathrm{y}=10.391 \mathrm{x}-6.3177$ & $\mathrm{y}=0.2009 \mathrm{x}+2.7916$ & $\mathrm{y}=0.0003 \mathrm{x}+3.8352$ \\
$\mathrm{R}^{2}$ & $\mathrm{R}^{2}=0.9339$ & $\mathrm{R}^{2}=0.9199$ & $\mathrm{R}^{2}=0.5468$ \\
\hline
\end{tabular}

By comparing $\mathrm{R}^{2}$ of the three models, it can be seen that Elovich equation and Two-constant equation have a high fitting degree for the washing kinetics of heavy metal $\mathrm{Pb}$ in contaminated soil, while First-order equation is not suitable for describing the washing kinetics. Therefore, the washing desorption process of $\mathrm{Pb}$ in soil by $\mathrm{HCl} \&$ Rhamnolipid is controlled by diffusion factors, and it is mainly a heterogeneous diffusion process. 


\section{Speciation distribution of $P b$ before and after washing}

The risks of heavy metal pollution to soil is directly related to their total concentration as well as their speciation distribution. In this study, we further compare the speciation changes of $\mathrm{Pb}$ in the soil before and after compound washing. The results are shown in Table 8 .

Table 8. Speciation distribution of $P b$ in soil before and after washing

\begin{tabular}{c|c|c|c|c|c|c}
\hline \multirow{2}{*}{ Pb speciation } & \multicolumn{2}{|c|}{ Before washing } & \multicolumn{2}{c|}{ HCl \& EDTA } & \multicolumn{2}{c}{ HCl \& Rhamnolipid } \\
\cline { 2 - 7 } & $\begin{array}{c}\text { Content } \\
\left(\mathrm{mg} \cdot \mathrm{kg}^{-1}\right)\end{array}$ & $\begin{array}{c}\text { Percentage } \\
(\%)\end{array}$ & $\begin{array}{c}\text { Content } \\
\left(\mathrm{mg} \cdot \mathrm{kg}^{-1}\right)\end{array}$ & $\begin{array}{c}\text { Percentage } \\
(\%)\end{array}$ & $\begin{array}{c}\text { Content } \\
\left(\mathrm{mg}^{\circ} \mathrm{kg}^{-1}\right)\end{array}$ & $\begin{array}{c}\text { Percentage } \\
(\%)\end{array}$ \\
\hline Acid extractable & 1426.50 & 19.02 & 350.35 & 12.47 & 240.70 & 10.14 \\
Reducible & 2058.00 & 27.44 & 233.75 & 8.32 & 141.24 & 5.95 \\
Oxidizable & 1192.50 & 15.90 & 272.52 & 9.70 & 190.14 & 8.01 \\
Residual & 2823.00 & 37.64 & 1952.88 & 69.51 & 1801.67 & 75.9 \\
Total & 7500.00 & 100.00 & 2809.50 & 100.00 & 2373.75 & 100 \\
\hline
\end{tabular}

Table 8 shows that $\mathrm{Pb}$ in contaminated soils of the smelter exists mainly in the form of Residual and Reducible, accounting for $37.64 \%$ and $27.44 \%$, respectively, indicating that $\mathrm{Pb}$ forms a stable crystal structure with soil or firmly binds with clay minerals. After compound washing, the speciation distribution of $\mathrm{Pb}$ in soil changed greatly, and the concentration of all forms decreased significantly, indicating that the compound eluents of $\mathrm{HCl} \& \mathrm{EDTA}$ and $\mathrm{HCl} \&$ Rhamnolipid could release $\mathrm{Pb}$ in various forms.

The Acid extractable is the most susceptible metal form to washing, and it is very sensitive to $\mathrm{pH}$ changes, and can be easily eluted when the $\mathrm{pH}$ is reduced. Therefore, the addition of $\mathrm{HCl}$ among the compound eluent greatly reduced the content of acid extractable $\mathrm{Pb}$ in the soil. Reducible mainly refers to heavy metals bound by $\mathrm{Fe}$ and $\mathrm{Mn}$ oxides in soil (Shen et al., 2007). The content of reducible $\mathrm{Pb}$ in soil also decreased significantly, which is mainly due to the high content of Fe and $\mathrm{Mn}$ in the soil polluted by this smelting site. A large amount of $\mathrm{Fe}$ and $\mathrm{Mn}$ are extracted at the same time in the process of composite washing, which leads to the decrease of $\mathrm{Pb}$ content in the form of Fe and Mn oxides in soil. The Oxidizable mainly refers to heavy metals bound by organic matter and sulfide in soil. The higher the content of organic matter in soil, the better the extraction of Oxidizable (i.e. organic matter bound) (Li et al., 1996). The content of organic matter in the soil used in this study is relatively high, so the content of Oxidizable $\mathrm{Pb}$ has also decreased significantly after complex washing. The properties of Residual are usually stable, and they usually exist in silicate, primary minerals and secondary minerals (Barona et al., 2001). The residual $\mathrm{Pb}$ in soil also decreases to some extent after complex washing, which may be due to the release of some residual $\mathrm{Pb}$ accompanied by silicate dispersion.

\section{Conclusion}

In this study, single and compound eluents were applied to washing remediate the soils with $\mathrm{Pb}$ contamination intensity of $7500 \mathrm{mg} \cdot \mathrm{kg}^{-1}$ in an abandoned non-ferrous metal smelter in Yunnan China. The results showed that when the compound ratio of $\mathrm{HCl}$ $\left(1 \mathrm{~mol} \cdot \mathrm{L}^{-1}\right) \&$ Rhamnolipid (2\%) was 1:1, the liquid-solid ratio was 10:1, and the washing 
time was $1080 \mathrm{~min}$, the removal rate of $\mathrm{Pb}$ in the soil was $68.35 \%$, which met "Risk screening value for soil contamination of the development land" $\left(\mathrm{Pb}<2500 \mathrm{mg} \cdot \mathrm{kg}^{-1}\right)$ in "soil environmental quality standard China (GB36600-2018)". The washing desorption process of $\mathrm{Pb}$ in soil conforms to Elovich model and is mainly a heterogeneous diffusion process. In addition, from the distribution of $\mathrm{Pb}$ forms in soil, the main forms of $\mathrm{Pb}$ in the waste smelter soil are acid extractable and reducible. The active $\mathrm{Pb}$ was effectively removed, which greatly reduced the biological toxicity and environmental risk of the soil.

The heavy metals in the contaminated soil are eventually transferred to the washing waste liquid, so the recovery and treatment of the washing waste liquid should be further studied in the future. In addition, this study mainly simulated the ectopic washing process of contaminated soil, and the amount of soil used in the experiment was less. Therefore, the soil column washing experiment could be conducted by simulating the in-situ washing process in the future.

Acknowledgements. This work was financially supported by the National Water Pollution Control and Treatment Science and Technology Major Project (2015ZX07406005), and Preparation Project of Education Material for Soil Environmental Protection Publicity of Ministry of Ecology and Environment of People's Republic of China (H201606).

\section{REFERENCES}

[1] Abumaizar, R. J., Smith, E. H. (1999): Heavy metal contaminants removal by soil washing. - Journal of Hazardous Materials 70(1-2): 71-86.

[2] Ashraf, M. A., Maah, M. J., Yusoff, I. (2012): Chemical Speciation and Potential Mobility of Heavy Metals in the Soil of Former Tin Mining Catchment. - The Scientific World Journal 2012: 1-11.

[3] Bacon, J. R., Dinev, N. S. (2005): Isotopic characterisation of lead in contaminated soils from the vicinity of a non-ferrous metal smelter near Plovdiv, Bulgaria. - Environmental Pollution 134(2): 247-255.

[4] Barona, A., Aranguiz, I., Elías, A. (2001): Metal associations in soils before and after EDTA extractive decontamination: Implications for the effectiveness of further clean-up procedures. - Environmental Pollution 113(1): 79-85.

[5] Burges, A., Epelde, L., Blanco, F., Becerril, J. M., Garbisu, C. (2017): Ecosystem services and plant physiological status during endophyte-assisted phytoremediation of metal contaminated soil. - Science of The Total Environment 584-585: 329-338.

[6] Chen, F., Luo, Z., Liu, G., Yang, Y., Zhang, S., Ma, J. (2017): Remediation of electronic waste polluted soil using a combination of persulfate oxidation and chemical washing. Journal of Environment Management 204(Pt 1): 170.

[7] Cui, W., Li, X., Zhou, S., Weng, J. (2007): Investigation on process parameters of electrospinning system through orthogonal experimental design. - Journal of Applied Polymer Science 103(5): 3105-3112.

[8] de Andrade Lima, L. R. P., Bernardez, L. A. (2017): Characterization of the soil contamination around the former primary lead smelter at Santo Amaro, Bahia, Brazil. Environmental Earth Sciences 76: 470.

[9] Dermont, G., Bergeron, M., Mercier, G., Richer-Laflèche, M. (2008): Soil washing for metal removal: A review of physical/chemical technologies and field applications. Journal of Hazardous Materials 152(1): 1-31.

[10] Li, Z., Shuman, L. M. (1996): Redistribution of forms of zinc, cadmium and nickel in soils treated with EDTA. - Science of The Total Environment 191(1-2): 95-107.

[11] Li, Z., Ma, Z., van der Kuijp, T. J., Yuan, Z., Huang, L. (2013): A review of soil heavy metal 
pollution from mines in China: Pollution and health risk assessment. - Science of The Total Environment 468-469: 843-853.

[12] Moutsatsou, A., Gregou, M., Matsas, D., Protonotarios, V. (2006): Washing as a Remediation Technology Applicable in Soils Heavily Polluted by Mining-Metallurgical Activities. - Chemosphere 63(10): 1632-1640.

[13] Nitschke, M., Costa, S. G., Contiero, J. (2010): Rhamnolipid surfactants: An update on the general aspects of these remarkable biomolecules. - Biotechnology Progress 21(6): 15931600 .

[14] Park, J., Jung, Y., Han, M., Lee, S. (2002): Simultaneous Removal of Cadmium and Turbidity in Contaminated Soil-Washing Water by DAF and Electroflotation. - Water Science and Technology 46(11-12): 225-230.

[15] Qiao, J., Sun, H., Luo, X., Zhang, W., Mathews, S., Yin, X. (2017): EDTA-assisted leaching of $\mathrm{Pb}$ and $\mathrm{Cd}$ from contaminated soil. - Chomsphere 167: 422-428.

[16] Reza, S. K., Baruah, U., Singh, S. K., Das, T. H. (2015): Geostatistical and multivariate analysis of soil heavy metal contamination near coal mining area, Northeastern India. Environmental Earth Sciences 73(9): 5425-5433.

[17] Shen, J., Liu, E., Zhu, Y., Hu, S., Qu, W. (2007): Distribution and chemical fractionation of heavy metals in recent sediments from Lake Taihu, China. - Hydrobiologia 581(1): 141150.

[18] Tessier, A., Campbell, P. G. C., Bisson, M. (1979): Sequential extraction procedure for the speciation of particulate trace metals. - Analytical chemistry 51(7): 844-851.

[19] Voglar, G. E., Leštan, D. (2011): Efficiency modeling of solidification/stabilization of multi-metal contaminated industrial soil using cement and additives. - Journal of Hazardous Materials 192(2): 753-762.

[20] Wei, M., Chen, J., Wang, X. (2016): Removal of arsenic and cadmium with sequential soil washing techniques using Na2EDTA, oxalic and phosphoric acid: Optimization conditions, removal effectiveness and ecological risks. - Chemosphere 156: 252-261.

[21] Wen, J., Stacey, S. P., Mclaughlin, M. J., Kirby, J. K. (2009): Biodegradation of rhamnolipid, EDTA and citric acid in cadmium and Zn contaminated soils. - Soil Biology Biochemistry 41(10): 2214-2221.

[22] Zhang, W., Huang, H., Tan, F., Wang, H., Qiu, R. (2010): Influence of EDTA washing on the species and mobility of heavy metals residual in soils. - Journal of Hazardous Materials 173(1-3): 369-376.

[23] Zhao, P., Ge, S., Yoshikawa, K. (2013): An orthogonal experimental study on solid fuel production from sewage sludge by employing steam explosion. - Applied Energy 112: 1213-1221.

[24] Zhou, D., Li, Z., Luo, X., Su, J. (2017): Leaching of rare earth elements from contaminated soils using saponin and rhamnolipid bio-surfactant. - Journal of Rare Earths 35(9): 911919.

[25] Zuo, W., Jiaqiang, E., Liu, X., Peng, Q., Deng, Y., Zhu, H. (2016): Orthogonal Experimental Design and Fuzzy Grey Relational Analysis for emitter efficiency of the micro-cylindrical combustor with a step. - Applied Thermal Engineering 103: 945-951. 